\title{
Efficacy and side effects of mianserin, a tetracyclic antidepressant
}

\author{
A. WAKELING \\ Ph.D., B.Sc., F.R.C.Psych., D.P.M.
}

Academic Department of Psychiatry, Royal Free Hospital School of Medicine, London NW3 2PF

\section{Introduction}

Antidepressant drugs have been in extensive use for over 20 years. Initially 2 groups of compounds, the monoamine oxidase inhibitors (MAOI) and tricyclic compounds based on the imipramine configuration were widely used. In the early 1960 's after a few years of wide use, interest in the MAOI group fell following the recognition of a serious adverse effect. Blackwell (1963) described the occurrence of hypertensive crisis with occasional fatalities when these compounds were taken with certain foodstuffs. It is of interest, however, that in recent years there has been some resurgence of interest in these compounds and the suggestion that their dangers may have been exaggerated (Tyrer, 1979) or might be ameliorated by combination with tricyclics (Pare et al., 1982). Interest in the tricyclic group however has continued unabated and over the years at least 20 antidepressants based on the original imipramine configuration have been produced. There is now a widespread and extensive accumulated experience of these compounds and although they remain the most widely prescribed antidepressant, it is now clear that they have a number of serious disadvantages. The most important of these are cardiotoxicity, potential fatality in overdose, marked peripheral anticholinergic activity and reduction in seizure threshold (Blackwell, 1981a). As these disadvantages exist to some extent with all the tricyclics produced so far, there have, not surprisingly, been active attempts to produce different and safer antidepressant compounds.

Over the last few years a number of different compounds have come into use as antidepressants and these constitute the 'second generation' antidepressant drugs. Included among these are; viloxazine and zimelidine, both bicyclic compounds; nomifensine, a tetrahydro-isoquinoline derivative; maprotiline, a bridged tricyclic compound and the tetracyclic compound mianserin. All differ somewhat in their actions on central neurotransmitter systems and differing claims are made that their antidepressant actions are relatively free from the adverse or unwanted effects of the tricyclics. These claims should be received with caution as there has been an insufficient experience in the use of many of them. Mianserin, however, is probably the most widely used of these compounds and considerable clinical experience of its use has been accumulated over the last few years.

\section{Mianserin}

Mianserin is a tetracyclic compound structurally distinct from both the classical tricyclic antidepressants and from bridged tricyclics of the maprotiline type. It was originally designed as an anti-allergic drug, but early trials suggested mood elevating qualities and in 1972 antidepressant-like central nervous system activity was detected by computerized electroencephalographic studies in volunteers (Itil, Polvan and Hsu, 1972). Subsequently, a variety of clinical trials have indicated that mianserin possesses antidepressant activity equal to that of the widely-used tricyclic antidepressants.

\section{Efficacy}

There are particular difficulties in assessing the efficacy of new putative antidepressant compounds. The most rigorous tests of efficacy involve the use of randomized placebo-controlled double-blind clinical trials utilizing large numbers of patients, with standardized and validated procedures used for clinical diagnosis and assessment. However the use of placebo in patients with severe depressive illness when there are well-tried effective treatments raises serious ethical issues. Due to this, new antidepressant compounds are usually compared in trials with standard tricyclic antidepressants. Such trials not surprisingly can give rise to complex problems of interpretation. 
Placebo controlled trials. Smith, Naylor and Moody (1978) demonstrated the superiority of mianserin over placebo in an important trial including 41 severely depressed women. However, this trial lasted only 2 weeks because of the ethical considerations involved. Two further placebo controlled trials utilizing mildly depressed patients suggested active antidepressant effect for mianserin (Murphy, Donald and Molla, 1976; Branconnier, Cole and Ghazvinian, 1981).

Comparison with tricyclic antidepressants. A large number of double-blind trials of varying methodological sophistication comparing mianserin with standard tricyclic antidepressants have been reported (Pinder and Fink, 1982). These include comparison with amitriptyline (Wheatley, 1975; Coppen et al., 1976; Montgomery et al., 1978; Murphy and Bridgeman, 1978; Daly, Brown and Morgan, 1979; Kretschmar, 1980) with imipramine (Murphy, 1975; Pichot, Dreyfus and Pull, 1978) and with clomipramine (Blaha, Pinder and Stulemeijer, 1980; De Buck, 1980). The detection of differences in efficacy between 2 compounds both having active properties, in small groups of patients is difficult. It is therefore perhaps not surprising that almost all of these comparisons between mianserin and tricyclics have concluded that they are indistinguishable in efficacy and onset of action. An important factor however emanating from these trials is the apparent paucity of side effects emerging on treatment with mianserin. Daily dosage in these studies ranged from $20-30 \mathrm{mg}$ for mianserin and $75-300 \mathrm{mg}$ for the tricyclics.

\section{Side effects}

Mianserin has sedative properties and drowsiness is the most frequently reported side effect. However, this often diminishes within the first week. The clinical trials suggest that peripheral anticholinergic effects are rare and occur to a less extent than with tricyclics. These observations from therapeutic trials are supported by experimental double-blind studies in depressed patients (Ghose, Coppen and Turner, 1976; Wilson, Petrie and Ban, 1980) and in normal volunteers (Kopera, 1980).

A further important feature emerging from clinical trials with mianserin is an apparent lack of cardiovascular problems such as increased heart rate and hypotension. Burgess et al. (1979), in an analysis of the cardiovascular effects of mianserin and other antidepressants, reported that mianserin lacked the cardiotoxic and negative inotropic effects of the tricyclic antidepressants. Experimental studies in intact animal hearts, whole animals and in healthy subjects further demonstrate a lack of cardiotoxicity for mianserin (Harper and Hughes, 1977; Kopera et al., 1980).
The lack of cardiotoxicity with mianserin is 3 probably associated with its apparent safety in $\stackrel{\varnothing}{\varrho}$ overdose. Overdosage with mianserin commonly $\subseteq$ causes drowsiness, but there is an absence of the more serious complications found in tricyclic or maprotil- $\stackrel{5}{\rightarrow}$ ine overdose. Shaw (1980) in a survey of 84 cases of mianserin overdose from the London Poisons Unit $\frac{\bar{\sigma}}{\bar{\sigma}}$ reported no deaths and an absence of cardiac $\vec{\odot}$ arrhythmias and convulsions. Management of mian- $\odot$ serin overdosage is limited to gastric lavage within $\%$ the first $2 \mathrm{hr}$ after ingestion, with monitoring of vital $\vec{\circ}$ functions. In contrast to Shaw's findings however, Edwards (1979) reporting data from the Committee $\vec{\omega}$ on Safety of Medicines indicates that mianserin accounts for about $11 \%$ of reported antidepressant 6 related convulsions. This clearly requires continuing 3 observation and draws attention to the need for full 6 reporting to the relevant safety bodies of all adverse 8 drug effects. The other serious side effect of mian- 0 serin is the occasional occurrence of blood dyscrasias. N

Blood dyscrasias. Between January 1974 and October 1981, the Committee on Safety of Medicines received 17 reports of blood dyscrasias associated with mianserin. These included 7 cases of agranulo- $\frac{}{0}$ cytosis, 8 cases of granulocytopenia, one case of generalized leucopenia and one case of pancyto $\vec{\theta}$ penia. Curson and Hale (1979) and McHarg and McHarg (1979) published some details on 2 of these cases. Four of them were reported to the Australiam Drug Evaluation Committee (1980) following the introduction of mianserin in Australia in April 1978. Adams et al. (1983), in this journal, provide clinical $\mathbb{D}$ details on a further 4 of these cases, one of whom died. In the last few months, 2 additional cases of mianserin-induced agranulocytosis have been reported (Page, 1982; Achar, 1982).

White cell depression usually occurs early, typically at between 4 and 6 weeks after the start of treatment. It typically presents with oral ulceration and a sore throat. The neutrophil count in most of 3 these cases was severely reduced to $0.2 \times 10^{4} /$ litre or less, but, typically, complete recovery occurred once the drug was withdrawn.

This association of mianserin with a small number of cases of blood dyscrasia should be viewed against $\frac{7}{0}$ the background that all psychotropic drugs are reported as being associated with some form of blood $N$ dyscrasia. Nevertheless, it dictates that all patients N receiving mianserin should be carefully observed $N$ particularly during the first few weeks of treatment. In the event of the patient developing symptoms of infection such as fever, stomatitis or sore throat the $\stackrel{\circ}{工}$ drug should be stopped immediately and full haematological investigation started. It might be prudent, where possible, for patients to have regular blood counts with a particular focus at between 4 and $6 \underset{\mathbb{D}}{\overparen{D}}$ weeks. It should be emphasized however that the key $\frac{?}{\mathbb{D}}$ 
to the early detection of side effects is regular careful and direct clinical observation of patients.

\section{Conclusions}

There is evidence to indicate that mianserin has antidepressant activity. It is generally well tolerated and appears to have a low propensity for interaction with many of the commonly used drugs. Due to its apparent lack of serious side effects, particularly the absence of cardiotoxicity and anticholinergic effects and its safety in overdosage, it is now in widespread use. It is widely used in general practice and primary care settings particularly among the elderly and those with medical and cardiovascular problems. The recent reports of severe blood dyscrasias in a few patients receiving mianserin should, however, induce caution. Blackwell (1981b) has cogently pointed out 'that a consistent feature of the literature on all psychotropic drugs is the extended time periods that occur between the introduction of a new compound and the discovery of its full range of adverse effects'. $\mathrm{He}$ calls attention to the fact that new side effects such as speech blockage are being recognized after 20 years of extensive use of the tricyclic antidepressants. It is important, therefore, to maintain a high level of vigilance in the use of all psychotropic drugs and to be alert to the possibility of new adverse effects arising in apparently safe compounds.

Antidepressants are powerful drugs and as yet their mode of action is incompletely understood. There is a consensus of opinion that these compounds are overprescribed particularly in the primary care setting. Yet it is precisely here that high standards of clinical monitoring are often lacking.

\section{References}

ACHAR, K.N. (1982) Mainserin induced agranulocytosis. British Medical Journal, 285, 208.

Adams, P.C., Robinson, A., Reid, M.M., VishU, M.C. \& LivingSTONE, M. (1983) Blood dyscrasias and mianserin. Postgraduate Medical Journal, 59, 31.

ADVERSE DRUG REACTIONS ADVISORY COMMITTEe (1980) Medical Journal of Australia, ii, 673.

BLACKWELL, B. (1963) Hypertensive crisis due to MAOI. Lancet, ii, 849.

BLACKWELL, B. (1981a) Adverse effects of antidepressant drugs. Part I: Monoamine oxidase inhibitors and tricyclics. Drugs, 21, 201.

BLACKWELL, B. (1981 b) Adverse effects of antidepressant drugs. Part 2: Second generation antidepressant and rational decision making in antidepressant therapy. Drugs, 21, 273.

Blaha, L., Pinder, R.M. \& Stulemeijer, S.M. (1980) Doubleblind trial of mianserin versus clomipramine. Current Medical Research and Opinion, 6 (suppl. 7), 99.

Branconnier, R.J., Cole, J.O. \& Ghazvinian, S. (1981) The therapeutic profile of mianserin in mild elderly depressives. Psychopharmacology Bulletin, 17, 129.

Burgess, C.D., MONTGOMERY, S., WADSWORTh, J. \& TURNER, L. (1979) Cardiovascular effects of amitriptyline, mianserin, zimelidine and nomifensin in depressed patients. Postgraduate Medical Journal, 55, 704.

Coppen, A., Gupta, R., Montgomery, S., Ghose, K., Balley, J.,
BURNS, B. \& DE RIDDER, J.J. (1976) Mianserin hydrochloride: a novel antidepressant. British Journal of Psychiatry, 129, 342.

Curson, D.A. \& HALE, A.S. (1979) Mianserin and agranulocytosis. British Medical Journal, 1, 378.

Daly, R.J., Browne, P.J. \& Morgan, E. (1979) Mianserin in the treatment of depressive illness. A comparison of amitriptyline. Irish Journal of Medical Science, 148, 145.

DE BUCK, R. (1980) A comparison of the efficacy and side effects of mianserin and clomipramine in primary depression: a double blind randomized trial. Current Medical Research and Opinion, 6 (suppl. 7), 88.

EDWARDS, J.G. (1979) Antidepressants and convulsions. Lancet, ii, 1368.

Ghose, K., Coppen, A. \& TURner, L. (1976) Autonomic actions and interactions of mianserin hydrochloride (Org. GB 94) and amitriptyline in patients with depressive illness. Psychopharmaco$\log y, 49,201$.

HARPER. B. \& HUGHES, I.E. (1977) A comparison in rabbit isolated hearts of the dysrhythmogenic potential of amitriptyline, maprotiline and mianserin in relation to their ability to block noradrenaline uptake. British Journal of Pharmacology, 59, 651.

ITIL, T.M., Polvan, N. \& HsU, W. (1972) Clinical and EEG effects of GB 94, a tetracyclic antidepressant. Current Therapy Research, 14, 395.

KOPERA, H. (1980) Anticholinergic effects of mianserin. Current Medical Research and Opinion, 6 (suppl. 7), 132.

Kopera, H., Fluch, N., Harpf, H., Klein, W.W. \& StulemeiJer, S.M. (1980) Cardiovascular effects of mianserin. A comparative study with amitriptyline and a placebo in healthy subjects. International Journal of Clinical Pharmacology, 18, 104.

KRETSCHMAR, J.H. (1980) Mianserin and amitriptyline in elderly hospitalised patients with depressive illness: a double blind trial. Current Medical Research and Opinion, 6 (suppl. 7), 144.

MCHARG, A.M. \& MCHARG, J.F. (1979) Leucopenia in association with mianserin treatment. British Medical Journal, 1, 623.

Montgomery, S.A., Cronholm, B., Asberg, M. \& Montgom. ERY, D.B. (1978) Differential effects on suicidal ideation of mianserin, maprotiline and amitriptyline. British Journal of Clinical Pharmacology, 5 (suppl. 1), 778.

MURPHY, J.E. (1975) A comparative trial of Org GB 94 and imipramine in the treatment of depression in general practice. Journal of International Research, 3, 251.

MURPHY, J.E. \& BRIDGEMAN, K.M. (1978) A comparative trial of mianserin and amitriptyline in the treatment of depression in general practice. Journal of International Medical Research, 6, 199.

MURPHY, J.E., DonALD, J.F. \& Molla, A.L. (1976) Mianserin in the treatment of depression in general practice. Practitioner, 217, 135.

PAGE, C.E. (1982) Mianserin induced agranulocytosis. British Medical Journal, 284, 1912.

Pare, C.M.B., Kline, N., Hallstrom, C. \& Cooper, T.B. (1982) Will amitriptyline prevent the 'cheese' reaction of monoamine oxidase inhibitors. Lancet, ii, 183.

Pichot, P., Dreyfus, J.F. \& PUll, C. (1978) A double blind multicentre trial comparing mianserin and imipramine. British Journal of Clinical Pharmacology, 5 (suppl. 1), 87 S.

PINDER, R.M. \& FINK, M. (1982) Mianserin. In: Modern Problems of Pharmacopsychiatry (ed. T. A. Blau). Karger, Basel.

SHAW, W.L. (1980) The comparative safety of mianserin in overdose. Current Medical Research and Opinion, 6 (suppl. 7), 44.

Smith, A.H.W., NAYloR, G.S. \& Moody, J.P. (1978) Placebocontrolled double-blind trial of mianserin hydrochloride. British Journal of Clinical Pharmacology, 5 (suppl. 1), 678.

TYRER, P. (1979) Clinical use of monoamine oxidase inhibitors. In: Psychopharmacology of Affective Disorders (eds E. S. Paykel and A. Coppen), p. 159. Oxford, University Press, Oxford.

WhEATLEY, D. (1975) Controlled clinical trial of a new antidepressant (Org GB 94) of novel chemical formulation. Current Therapy Research, 18, 849.

Wilson, W.H., PeTrie, W.M. \& BAN, T.A. (1980) Possible lack of anticholinergic effects with mianserin: a pilot study. Journal of Clinical Psychiatry, 41, 63. 